\title{
Interviews
}

\section{Interview with Joseph Bachana, President of DPCI}

\section{Joseph Bachana}

is President of DPCl, an interactive technology agency that delivers integrated content management solutions for organizations that need to deliver information and content across a range of channels. Contact him at joseph.bachana@databasepublish.com

\section{Keywords: DAM, workflow, ingest, content, current state, project management}

Abstract Michael Moon interviews Joseph Bachana, President of DPCl, on his insights concerning the implementation of DAM and related workflows.

Journal of Digital Asset Management (2007) 3, 281-287. doi:10.1057/palgrave.dam.3650104
Joseph Bachana President, DPCI 1560 Broadway, Suite 810 (@46th Street) New York, NY 10036 Tel: +12125755609 Fax +1 2125755653 E-mail: joseph.bachana@ databasepublish.com
MM: We have Joe Bachana - President of DPCI. DPCI is an interactive technology agency based in New York City. It delivers integrated content management and digital asset management systems.

Hello, Joe!

JB: Hi, there!

MM: I wanted to follow up. Did I give a good characterization of your background, there?

JB: Sure. That's pretty much what our company specializes in. We're helping customers with their content-management needs. To us, those include interactive websites, backed by powerful content management repositories, including DAM.

MM: In your article, you introduced the notion of things that go well or don't go well, in terms of implementing DAM and related workflows.

Could you just summarize the things that you have? Again, in the context of our readership - for the most part, the people reading the Journal of DAM already have probably a DAM system - a repository.

JB: They've begun to do 1 of 2 things. Move upstream in terms of the content or asset-creation process - focusing on automated workflows that might include more comprehensive scheduling and project-management - as well as review and approval systems. As well as moving downstream into more automated publishing or content workflows.

The idea is that if you have the appropriate or well-designed content workflow, you'll get print and online publications or content from the same effort.

MM: Would you speak to that level of user or manager?

JB: Sure. Actually, if I could back up just for a second to say that the change-management notion of these kinds of projects is really about the "people" side of change. It's a more organized approach to the transition, no matter what the business requirements or the drivers are for implementing DAM.

We've seen - both in our implementations of DAM as well as in my association with the Henry Stewart Symposium and speaking with people throughout the industry - that you can pick the best technology and have the best implementation team, but your project may still fail. I would almost say that change management is the "special sauce" to the implementation. It's really about aligning individuals and teams with corporate objectives supported by technology. MM: Right. Joe - sometimes we refer to that as the $90-90$ rule. After you get 90 per cent of the work done, 90 per cent is left.

JB: That's good!

MM: And that second 90 per cent is always the socialization of the change agenda, and the actual management of how I'm going to be doing my work differently.

JB: In the past you have, and I see this all the time - a patriarchal approach. That could be driven from executive management or IT. 
The patriarchal approach is that management defines the requirements. They'll pick the DAM system. They'll pick the implementation partner.

Then the DAM system is implemented, everybody "high-fives" each other, but the staff resists using it. So the concept behind the "Field of Dreams" theme in my article centers around the "if you build it, they may not come!" That's what this is about.

MM: In that context, where we're going from a really strong, mature, departmental DAM to something that's more process-oriented.

What do you recommend? Or what do you see as a critical success factor - factors sequenced - in terms of facilitating that change?

JB: Great question. There's a certain type of DAM implementation, which is repository-based. It's simply an archive which allows users to access different types of content stored in the system.

MM: We're assuming people have that already. JB: Right. But when you start getting into an organization's workflow or changing their processes, you begin to change the nature of the content strategy itself (Figures 1 and 2).

MM: Give me an example of a shifting or an expanded content strategy.

JB: In the past, publishers had DAM systems in which they stored print images. Now they want to be able to interact. They want the Web-based editors and producers to be able to access the same content.

All of a sudden, you've got these new challenges. The opportunity is that somebody goes on a photo shoot for an auto show, and instead of having access to 2 or 3 photos, they could have hundreds of images that are in raw format.

But there's a whole new workflow and a whole new set of requirements for managing the rights to those assets. Who's going to be entering the metadata and describing these hundreds of images? Is this something that's automated?

How do you track where images were used? It requires a whole level of governance.

Then you've got the simple thing of who's going to do the cropping, color correcting and optimizing of these assets for use both on the Web or mobile devices, as well as potentially other print media.
MM: As companies move from a simple repository to more of an integrated workflow, or an automated workflow, where do those functions start to happen? Whether it's the tagging of assets, the certifying or clearing of them, and maybe even reworking the digital cosmetics or color retouch?

JB: All of the above. We try to start from the pain of all the different constituents in the process. We'll map out your source content.

Within the context of my example, in this case, if I said, "Auto Show," it would be presumably - a car. So it would follow the taxonomy of an automotive brand.

MM: Right.

JB: So we look at the photographer's workflow. Are they using a digital camera? What are they doing with those images? How are they getting uploaded into a specific environment? What's the workflow currently for the photo editor's selection process? Are there other publications that need access to these assets?

If this is a global company, do those images need to now be accessed by folks in offices in Europe or Asia?

Then you turn over after the selection process, and you now have a process around the workflow for optimizing those images for whichever media.

Currently, the way it's done is, people will optimize it for a specific medium. Like getting it ready for an Adobe InDesign layout. But you could also have the notion of getting it ready for multiple platforms within one workflow.

We want to try to understand - within the organization - how that group effort is currently aligned. Typically, you've got Web teams and print teams, and personnel in Europe may work independently from the folks in the US.

MM: In the course of understanding how they're aligned, does that entail creating a visual depiction? A workflow? A content flow? How do you start to do that?

JB: That is one tool. I think that we want to be able to elicit from the participants or constituents - we call them stakeholders in the whole process - what their vision is. What they're willing to try. Sometimes incubating workflows is better than saying, "This is how you're going to do it." 


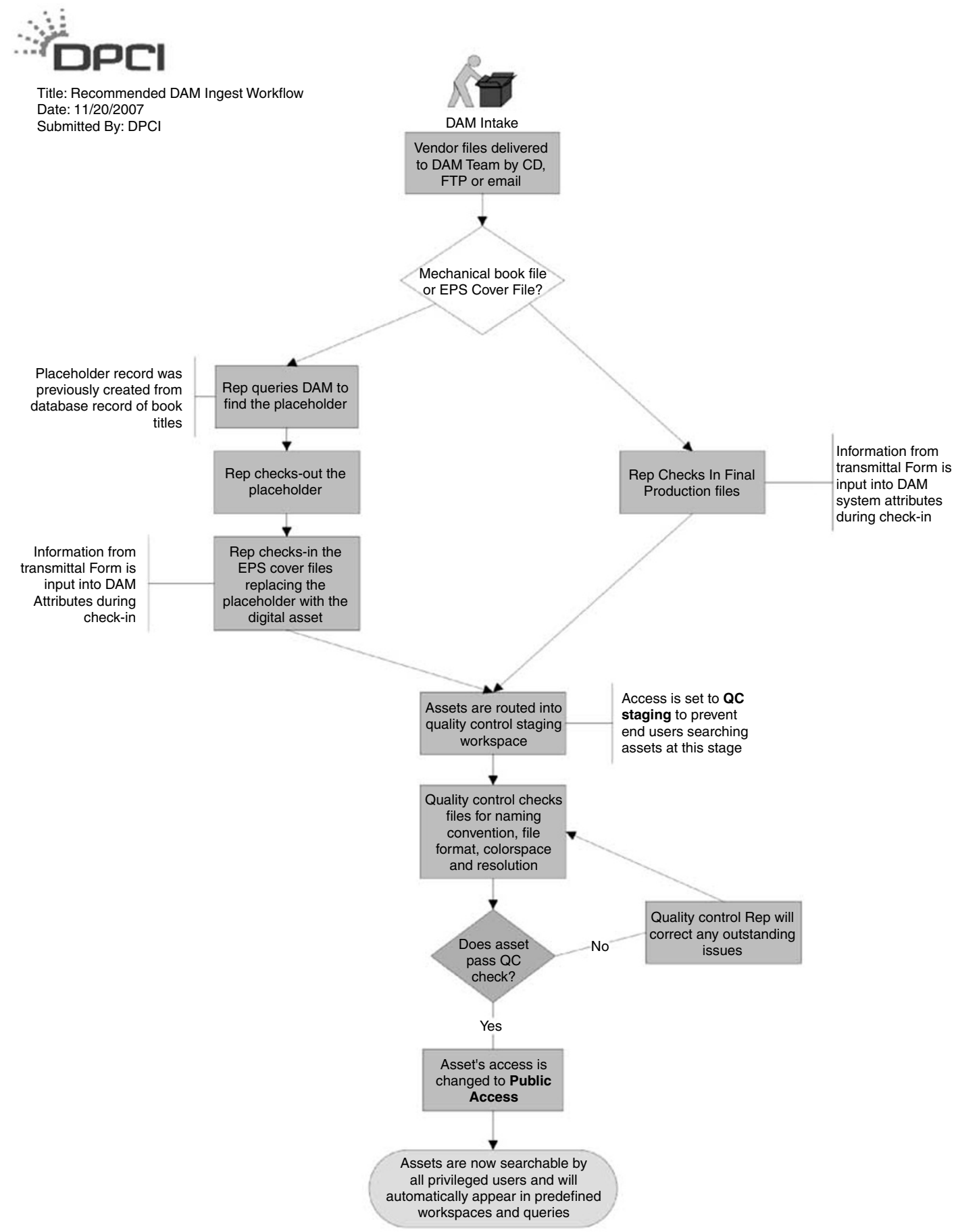

Figure 1: Future state asset ingest workflow for one client

For instance, if we do a current state workflow...

MM: Joe, that was my question. In terms of the state of workflow. How do you describe it?
JB: It's typically done with some sort of visual representation like a flowchart. Along with companion documentation that goes into the nuances of that workflow. 


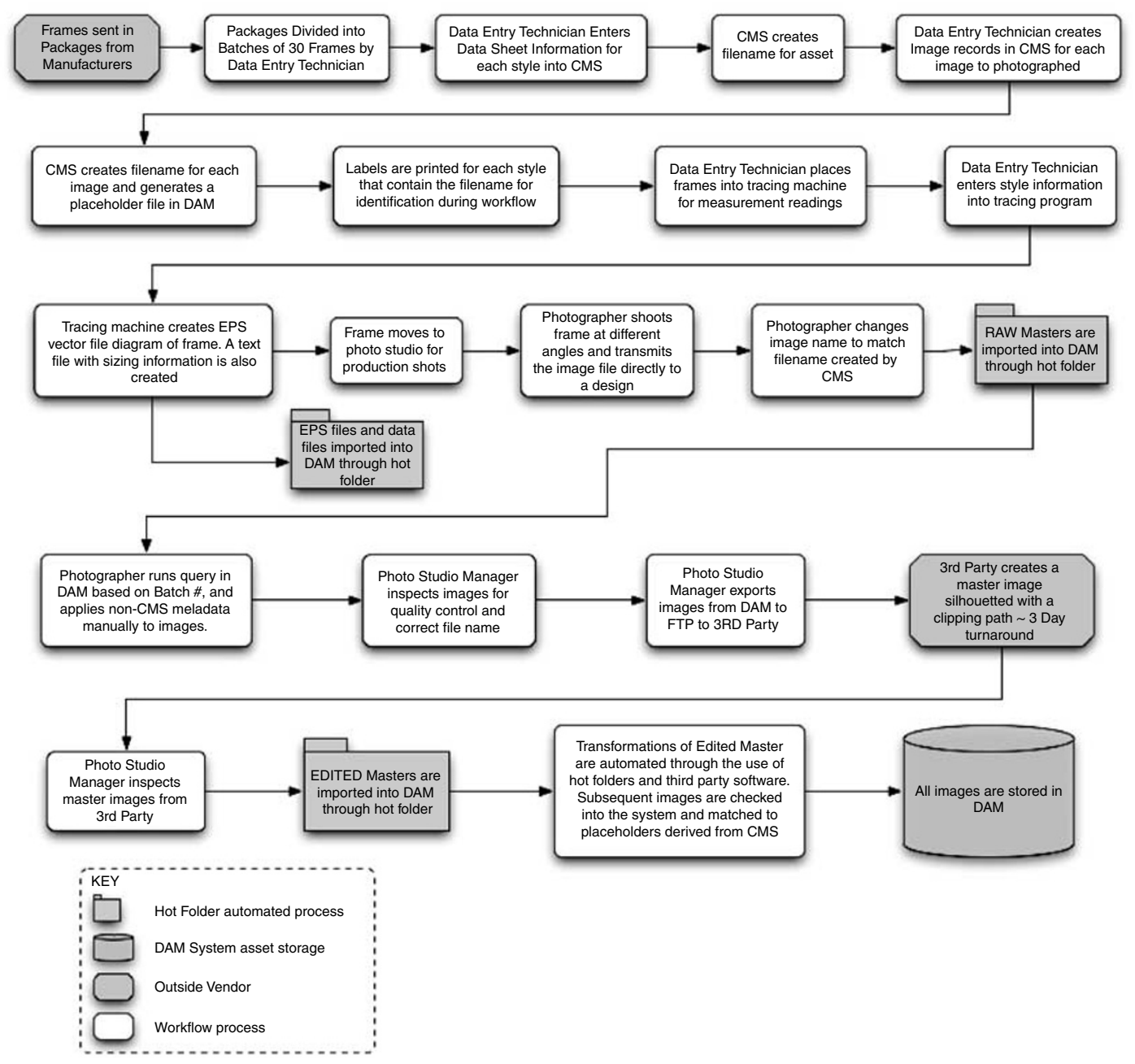

Figure 2: Future state asset ingest workflow for different client

We develop use-cases for specific activities. MM: How do you describe a use-case in that context?

JB: You first define who is the active participant(s) of a process. Then define their roles.

Inputs and outputs, essentially. That's what we visualize and map out.

MM: In the course of doing this, you're interviewing users and asking them, "What do you do right now?" Is that right? To get a current state workflow?

JB: Right. At that point, we're also trying to understand what the rate-determining steps are and what breakpoints are in the workflow. A ratedetermining step in a process is something that all subsequent points in a workflow depend upon.
It could be a point at which - if something doesn't happen, or happens slower than expected - subsequent steps cannot be executed within the workflow. You could have multiple ratedetermining steps in the process. You could have break points in the process, where somebody has to physically take something and move it to the next process.

MM: So both of those - rate-determining steps and breakpoints - represent critical junctures or weak links in an overall process?

JB: Correct. Yes.

We look at it in terms of people and process, first - before the technology. If you try to re-engineer process within the technology but the process itself is still broken, then people will 
actually blame the technology. That's another issue around asset-management.

People figure they'll implement a system and staff will just use this new process. But in fact, it's probably a better practice to get people to buy into this new process, and then reinforce it with the technology.

Using a scientific metaphor, this is similar to a catalytic chemical reaction. When you add an enzyme or a catalyst into a process, accelerated or improved outcomes can take place depending on when you have standard temperature or pressure. Same kind of a notion.

MM: You're looking at content workflows almost as a chemical or process engineer looks at a refinery?

JB: Exactly. Or as a biochemical reaction pathway. If you have a series of reactions, in fact, there are multiple chain reactions. Usually within a biological pathway, there are multiple processes that happen that spawn other processes.

Then if one fails and others don't, there could be a buildup of materials in one part or paucity in others.

At the end of the day, we're working to address dissatisfaction with the current state. If you really boil it down to change management, we're trying to get to the line of business performers or stakeholders in the process. We want to get to that, but at the same time, we also want to look at the IT department's pain points. They aren't necessarily about process. It might be about platform or that standard temperature and pressure that I was talking about.

MM: As you begin to work with your end user or stakeholders, you'd indicated that you begin to envision future state workflows. How do you do that? What sort of tools or props do you use to facilitate that envisioning process?

JB: If the question is with regard to a DAM system, we try as much as possible to have usability sessions or prototype sessions with people, to build out scenarios and reinforce them with DAM tools - so they can get a sense of what's possible.

Sometimes they can theorize a way of working that actually may not be cost-effective to implement with a DAM system. It might require a lot of customization. At that point, I think that's where you take the interactive approach — where people have stated issues with their workflow. They have some business requirements or opportunities that they're not meeting.

These kinds of systems are implemented to exploit opportunity, as well as to mitigate risk. If you can create prototypes or "incubate" what things would look like to satisfy the opportunities or risk, then I think people begin to feel more like they can own it.

These creative resources are typically kinesthetic and visual people. They like to touch and see the tools they're going to be using. If you give them a lot of words on paper, it may not work out for them. Diagrams and illustrations are ideal when you're mapping out future state.

The best way to do it, I think, is to actually get the users in lab settings. To teach them very early on what DAM is all about. And then try to nurture these new workflows within a practical setting.

MM: Cool!

What about your concept of change management champions? Could you describe who that is in an organization? And what do they do?

JB: Typically, you need an executive champion on these types of projects. Those are the folks that are going out there and saying, "You guys have to make that work. This is our vision for the business."

MM: Joe, doesn't that usually start with somebody that's in the trenches, saying, "Hey. There's got to be a better way of doing that?" He'll take it to a senior-level executive whom I'll call a "change sponsor" who says, "Sounds right. Go figure it out." Then he starts to go figure it out and comes back with a plan.

JB: But those guys don't necessarily make the best change managers. They could be the agents for change, in the sense that they're going to say, "There's got to be a better way," but are they going to help the company move from A to B to $\mathrm{C}$ ?

I've found that the visionary in the trenches as you put it tends to be a very strong personality to drive the DAM project forward. But they aren't necessarily great listeners to elicit feedback from peers, and build consensus.

From the standpoint of the change sponsor, as you put it - the executive that endorses the project - that is an indispensable role since that 
executive needs to broadcast early and often to all stakeholders "this is what we need to have as an outcome. We're all going to make this succeed. This is what the company's going to get out of it, this is what you're going to get out of it," and so forth. I have seen a recent project where an executive sponsor that was newly brought into the company was going around telling people he didn't believe in the initiative - now how do you think that project will turn out $6-12$ months from now?

However, neither the visionary nor the change sponsor - a term I like and am going to use going forward, Michael - are sufficient. You still need the role of the change manager, which we strongly advocate for our customers. That is the person that is working daily with all the participants in the DAM value chain to make sure that their workflow and business requirements are going to be met and that they will be "delighted" by this new solution.

MM: So that would be the person that's actually running the project?

JB: Not necessarily. But it could be. In a few implementations, I've seen this where they've assigned the project manager to a changemanagement role. For bigger initiatives, there's a good deal of work that has to happen around project management with regard to just managing scope, schedule, budget and quality as well as identifying and mitigating risk.

You could, on a smaller-scale project, have the project manager also doing change management. But recently I've seen companies that have had somebody doing change management who is in the role of a business or functional analyst, as opposed to the project manager. The important part of this is that this person is going out and constantly eliciting feedback from the users and stakeholders. The change manager has to be able to listen carefully for those stakeholders that might be murmuring under their breath, "This will never work," or, "Why do we need this now?" All the naysayers. MM: So you're saying, Joe, that this particular change manager must show up as relatively impartial, unbiased, a willing listener. Another way of saying that, "Doesn't have a dog in a fight."

JB: Yes. They're the advocates for the users. They're basically going back to the project manager and the implementation team, saying,
"This is what you need to do. This is the feedback I got from the usability sessions. This is what we need to do to make these people feel satisfied that we're meeting their needs."

MM: How often, Joe, have you found that a change manager actually comes in from the outside as an independent consultant that really is that neutral third party - as opposed to somebody who's part of the organization and may have an organizational agenda?

JB: This is not a science. This is something that's still germinating in my mind. For many years, we served as both the implementation experts, project managers, developers and change managers. But again, these are early results because I've been thinking a lot about change management in the last year. I'm testing some things on existing projects.

I'm starting to see results if the customer appoints an internal change manager. There are internal "family" squabbles or issues that a third party really cannot address as well as someone will from the inside who is mandated from the top to ensure end-user adoption of DAM.

MM: Another way of saying that, Joe, is that every company has a set of cultural norms. Tacit, unexamined assumptions - habituated routines by which it gets stuff done. When you're an outsider coming in, it takes often years before you get acclimated to those cultural norms. Before you're considered an insider. Right? JB: Well, but some of the change managers have actually been hired just for the project. I think it's more of a family thing. Change management is about people. There's sensitivity.

Let's put it this way... We have seen both scenarios and the jury's out on whether this could be more effective from an external role as a consultant or somebody internal. This is something I will continue to work on over the next few years and will hopefully have a clearer picture to present to the industry.

MM: But what you're saying, though, is that the change manager must bond with and be perceived by the users as "one of them?" JB: Yes. Additionally, they must not be perceived as somebody who's agenting, in the sense that they must not be representing the DAM solution. They must be prepared to hear that the system is not meeting the needs, so that they're not going to have wishful thinking. 
At first blush, my experience in implementing DAM solutions is that this role might be best suited for an internal type of functional/business analyst, working with a third-party resource to help drive the process. However, there are a few talented integrators that can also fill this role provided that they have the customer's interest first and not their own or that of the DAM vendor.

MM: So in the context of the journal here, you're calling attention to a new role. A new opportunity for somebody to kind of step into. As a kind of change-manager for "all things related digital workflows."

JB: It should definitely be somebody familiar with people resources. They should also be very good at subtly helping enhance workflows.

These aren't people that should be swashbuckling through somebody's workflow. That's where you run into issues.

MM: So this change-manger - if I hear you right - to summarize: one is that they're a really good listener, and they make the stakeholders feel like, "They're one of us. Representing our needs." However inarticulate those needs might be.

JB:Yes. Additionally, they should be great liaisons that can keenly summarize issues and challenges and report to the implementation team - whoever that may be.

MM: So those are distillers of insights? JB: Yes, distillers of insights. And there's got to be some courage in there, too, because the implementation teams might actually resist what they're hearing.

MM: It's more than courage. It's really two aspects. One is that they understand the nature of digital workflows and what's feasible and not feasible within that context. So they've got some technical chops or know-how, in terms of what's practical and pragmatic. And second, they're capable in the fine art of argumentation or persuasion from one technical tier to another.
JB: Yes, beyond just technical. I think in the simplest sense, they have to be the end-users' advocate. At the same time, they have to buy-in to the vision for the DAM system. Similar to the role of diplomacy at the United Nations. MM: Sure. It's almost a business ambassador... JB: Great term!

MM: ... That holds the context of the business, in terms of the objectives. The business moving towards fulfilling. 2 - advocates for the end-users or stakeholders. And formulates/distills the insights in terms of what's needed and wanted. And forms a persuasive argument for the technical team to get aligned with and to implement.

JB:Yes. But there are two more aspect to this. We want to have companies involving the same teams throughout the process. Both in problem identification, business case development, what the key success factors are for the project - and milestones. Things like product-selection decisions. The same team in project planning as well as usability and joint-application development sessions.

Quite frankly, because those people are going to be selling these systems that they've implemented to their peers, throughout. I can't tell you the number of times I've seen big companies get a project manager running around the country trying to sell a system that's already been implemented, and they just run smack up against the wall.

The second aspect is being prepared to make personnel changes. While naysayers, may give you ideas on how to improve the quality and performance of your DAM system, once the system is implemented, if they keep naysaying, that is going to be a problem for end user acceptance.

I think this should be stated within the change management context. You certainly don't want any individual poisoning the people or process. In my experience, it only takes one person to disparage your implementation. MM: Fair enough. 